Received: May, 2016

Accepted: September, 2016

ISSN $2006-6996$

\title{
PLANT GUM EXUDATES (KARAU) AND MUCILAGES, THEIR BIOLOGICAL SOURCES, PROPERTIES, USES AND POTENTIAL APPLICATIONS: A REVIEW
}

\author{
${ }^{*}{ }^{1}$ Sani Haruna, ${ }^{2}$ Bala Sidi Aliyu and ${ }^{1}$ Abdulhamid, Bala \\ 1,Department of Forestry Technology, Audu Bako College of Agriculture Dambatta, Kano. \\ ${ }^{2}$ Department of Plant Biology, Bayero University Kano, Nigeria \\ *Correspondence authors email:saniharuna27@gmail.com, GSM:08039569565
}

\begin{abstract}
This paper or review discusses the natural plant exudates and mucilages, their sources, properties and uses and the potential applications. Research in natural polymeric materials has witness growing interest and attention. This is attributable to a number of factors which include their relative abundance, low cost, biodegradable nontoxic, and ecofriendly profile.They are polymers that are mostly plant in origin with a vast applications.Polysaccharides hydrocolloids including gum and mucilage are abundant in nature and commonly found in many higher plants. These polysaccharides constitute a structurally diverse class of biological macromolecules with a broad range of physicochemical properties which are widely used for various applications in pharmacy, medicine, food and other non-food applications. In recent years those polymers derived from plants have evoke tremendous interest because of their industrial applications as diluent binders, thickening agents, smoothening, emulsifiers, gelling agents and stabilizers. This increasing research in this group of these plant materials are clear indications of their increasing importance.The fact for increase in importance of natural plant based materials is that plant resources are renewable and if cultivated or harvested in a sustainable manner, they can provide a constant supply of raw materials. To that effect, more understanding of their nature, physicochemical properties, sources, uses be gained so that can be used for wider applications.
\end{abstract}

Key words:, Polymer,GumExudate, Mucilage, Biological sources, Potential application

\section{INTRODUCTION}

In recent years plant derived polymers have evoked tremendous interest due to their diverse medicinal, pharmaceutical, food and non - food applications (Choudhari et al., 2014). These polymers are preferred over their synthetic counterpart because they are biocompatible, cheap and easily available than the synthetic ones. Demand for these substances is increasing and new sources are developed (Choudhari et al., 2014). Research in polymeric materials has witnessed growing interest and attention. This is attributable to a number of factors which include their relative abundance, low cost, biodegradable, non - toxic, inert and ecofriendly profile. This increasing research in this group of plant materials are clear indications of their increasing importance (Orgajie et al., 2011). Thus, it is believed that as technology and testing techniques advances, more understanding of their physicochemical nature, properties, sources, uses, would be gained that can enable them to be tailored for wider application than their synthetic ones (Orgajie et al., 2011).

Polysaccharides hydrocolloids including gum and mucilage are abundant in nature and commonly found in many higher plants. These polysaccharides constitute a structurally diverse class of biological macromolecules with a broad range of physicochemical properties which are widely used for various applications in pharmacy, medicine, food and other non- food application (Prajapati et al., 2013). Although mucilage can occur in higher concentration in different plant organs, their physiological function in most cases is unclear. Mucilage found in rhizome, roots and endosperm may act primarily as energy reserves whereas foliar mucilage appear not to serve as storage carbohydrate (Clifford et al., 2002). Due to the high concentrations of hydroxyl group in the polysaccharide mucilage generally have a water binding capacity and this has led to the studies in plant water retention. Gums are considered to be pathological products formed following injury to the plant or owing to unfavorable condition such as drought by a breakdown of cell walls (extracellular formation) while mucilages are generally normal products of metabolism formed within the cell (Intracellular formation) and or are produced without injury to the plant. Gum readily dissolve in water whereas mucilage form slimy masses (Jani et al., 2009). Gums are pathological products while mucilages are physiological products. Acacia, tragacanth, guar gum, kondagogu, tara gum, xanxan gum, cashew gum, are examples of plant gum while mucilages are often found in different parts of plants. For example in epidermal cell of leaves (Senna), in seed coat (lin seed), root (Mashmallow), fruit (okra), bark (Slippery elm) and middle lamella (Jani et al., 2009). 
Gums and mucilages have certain similarities, both are plant hydrocolloids. They are also translucent amorphous substances and polymers of a monosaccharide or mixed monosaccharide and many of them are considered with uronic acid. Gums and mucilages contain hydrophilic molecules which are combined with water to form viscous solution or gel (Parajapati et al., 2013). This paper discusses the natural plant exudates and mucilages their biological sources, properties uses and the potential applications. The aim is to highlight on these natural biopolymers (gum and mucilges), so that they can be used or adopted for more and wider applications and further to replace the use of the synthetic ones.

\section{CLASSIFICATION OF NATURAL GUM} EXUDATES AND MUCILAGES

Gums and mucilages are present in higher quantities in varieties of plants, seaweeds, fungi and other microbial sources where they perform a number of structural and metabolic functions. Plant source provide the largest amount (Rangari 2006).

The different available gums can be classified as follows. (Rishab et al., 2011)

1. According to charges- can be classified as:

Non-ionic seed gums e.g guar gum, locust bean gum, xanxan gum, tamarind gum, galactomannas, e.t.c.

Anionic gums e.g gum Arabic, karaya gum, tragacanth gum, gellan, tara, cashew gum, kondagogu, e.t.c.

2. According to the source

Plant origin :

Shrubs/tree exudates - Gum Arabic, Gum ghatti, Karaya gum, Kondagogu, Boswellia gum, Neem gum, Khaya gum, Albiza gum, Tara Gum,

Seed gum - Guar gum, Tamarind gum, Locust bean gum, larch gum e.t.c.

Microbial origin (Bacterial and Fungi):

Xanxan gum, Dextran gum, Letinan gum, Curdian, Cretine and Sclerigulucan, pullulan, zanflo, schizophyllan, Baker's yeast glycan, emulsan. e.t.c.

Animal origin :

Natural gums have also been obtained from animal sources, example include chitin, chitosan, chondroitin sulfate and hyaluronic acid.

3. classification based on shape:

According to the shape can be classified as,

- Short branched e.g. xanxan gum, and guar gum.

- Branch on branch e.g gum Arabic, karaya gum, Boswellia gum, cashew gum, hakea gum.

Classification of Mucilages:

1. Intracellular mucilages- e.g orchid species (corn), Agropyrum repense L. Beauvois (bulb), Alium cepa (bulb), Urgenia maritime, Aloe (soccuent part), Musa paradisiaca (pulp).

2. Cell membrane mucilage e.g Althea officinalis (root), Sinnamomum spp, Rhamnusfragula L. (bark) e.t.c.
3. Secreting hairs e.g Coffea arabica (leaf), Viola tricolor L. (leaf) e.t.c.

CHARACTERIZATION OF GUMS AND MUCILAGES

For characterization of gum and mucilages analytical techniques can be classified according to the type of information generated (Choudhary and Powar 2014)

Structural :

Gums and mucilages are polysaccharide and they contain sugars. Comfirmatory test can be done by chromatography (TLC/HPLC) and structure elucidation can be carried out by FTIR, mass and NMR spectroscopy.

\section{Purity:}

To determine the purity of the gum and mucilages test for alkaloids, glycosides, steroids, carbohydrates, flavonoids terpenoids, amino acid, saponins, oil and fat are carried out.

Toxicity:

The acute toxicity of gums and mucilages are determined by fixed-dose method as per OECD guide no. 425 (Mazunder et al., 2010).

Physicochemical properties:

Color, odor, taste, shape, texture, solubility, $\mathrm{pH}$, swelling index, hygroscopic nature, porosity can be estimated. The microbial load and presence of specific pathogens can also be determined. Gums and mucilages are highly viscous in nature, so the rheological properties are important criteria for describing their commercial use.

Chemical composition of gums and mucilages.

Gums and mucilages because of their polysaccharide nature, produce an indefinite number of monosaccharides on hydrolysis. Depending on the type hydrolysisproducts obtained they can be further classified into pentason (e.g. xylan) and hexosan (e.g. starch and cellulose). Gums as pathological products consists of calcium, potassium and magnesium salt of complex substances known as polyuronides. Mucilage are physiological products related to gum but they are generally sulphuric acid esters, the esters group being a complex polysaccharide. Both gums and mucilages are closely related to hemicellulose in composition, except that the sugars produced by hemicellulose are glucose mannose, and xylose, where as those produce by gum and mucilages are galactose and arabinose (Prajapati, 2013).

Advantages of natural gum and mucilages

The following are a number of the advantages of the natural plant based materials over synthetic ones (Reddy et al., 2013 and Jani et al., 2011).

\section{Biodegradable:}

Naturally available biodegradable polymers are produced by all living organisms. They represent truly renewable sources and they have no adverse impact on humans and environmental health e.g. skin and eye irritation. 
Biocompatible and non - toxic:

Chemically nearly all of these plant material are carbohydrates composed of repeating sugars (monosaccharide\} units. Hence they are non toxic.

Low cost:

It is always cheaper to use natural sources, the production cost is also much lower compared with that for synthetic materials.

\section{Environmentally friendly processing-}

Gums and mucilages form different sources are easily collected in different seasons in large quantities due to the simple production processes involved.

Local availability:

In developing countries governments promote the production of plant like guar gum and tragacanth because of the wide application.

Disadvantages of gum and mucilages:

Microbial contamination:

The equilibrium moisture content present in the gums and mucilages is normally $10 \%$ or more and structurally they are carbohydrate and during production, they are exposed to the external environment, so there is chance of microbial contamination.

Uncontrolled rate of dehydration:

Due to differences in the collection of natural materials at different time as well as differences in region, species, and climate conditions present in a given material may vary. There is a need to develop suitable monograph on available gums and mucilages.

\section{Reduced viscosity storage:}

Normally when gum and mucilages come in contact with water there is an increase in the viscosity of the formulation. Due to the complex nature of gums and mucilages (monosaccharide to polysaccharide and their derivatives). It has been found that after storage there is reduced viscosity.

\section{Batch to batch variation:}

Synthetic manufacturing is a controlled procedure with fixed quantities of ingredients, while the proportion of gums and mucilages is dependant on environmental and seasonal factors (Kottke et al., 2002)

\section{Biological sources of gum and mucilage Albizia gum}

The Albizia gum is obtained from the trunk of Albizia tree Albizia zygia from the family ( legumenosae) and the exudate is shaped like round elongated tears of variable colour ranging from yellow to dark brown (Reddy and Manjunath 2013). Albizia gum consists of B-1-3 - D- galactose units with some B- 1-6- linked D galactose units. Albizia gum has been investigated as a possible substitute for gum Arabic as a natural emulsifier for food and pharmaceuticals and also used as a binding and suspending agents (Bhaskar et al., 2013).

\section{Karaya gum.}

Karaya gum is the dried exudate from the tree Sterculia urens, family (Sterculiacea). The plant is common in tropical deciduous forest. When tho tree is incised or blazed, gum begins to ooze immediately. In natural state the gum is irregular in shape sometimes worm like in appearance. The gum when fresh may have an acetone odor. Actylated partial acidic hydrolysis gives D - galactose, L- rhamnose, 6-L -mannose and D-galacturonic acid along with aldobiouronic acids. The gum is used in pharmaceuticals as gelling agents, binders, adhesives, and used in cosmetics as bulk laxative and in food industries as stabilizers, emulsifiers, textile as manufacturers dye thickeners, paper industries as deflocculent and binder for light weight paper (Wallis,2005).

\section{Gum arabic}

Acacia gum, Indian gum or gum Arabica is the dried gummy exudates from the stems and branches of Acacia senegal (Leguminosae) or Acacia arabic. Acacia gum consistof a glycosidal acid of high molecular weight, which has been termed Arabic acid, combined withpotassium, magnesium and calcium. Structurally, gum Arabic is a branched molecule with the main chain consisting of 1 , 3linked $\beta-D$ galactopyranosyl unitswith other carbohydrates such as arabinose,glucuronic acid and rhamnose also present (Kokate, 2008). It isused as a general stabilizer in emulsions and used asan osmotic suspending and expanding agent toprepare a monolithic osmotic tablet system, bindingagent for tablets and emollient in cosmetics. Itsdemulcent properties are employed in various cough, diarrhea and throat preparations (Evans and Treese, 2007). It has widespreaduse in the food, drinks and other industries.

\section{Neem gum}

Neem gum exudate is obtained from the stem of Azadirachta indica family (Meliaceae). The exudate is a mixture of protein and polysugars. The protein are linked very tightly to the polysaccharide which constitute the major components (Brindha and Mallika, 2015). Presence of D-glucose, D-glucorunic acid, L- mannose, $\mathrm{L}-$ arabinose, xylose, $\mathrm{D}-$ glucosamine, aldoiuronic acid were reported (Brindha and Mallika 2015). Neem exudate is used in various industries for its commercial application. It is used in cosmetics paper (adhesive and strengthening), pharmaceutical (antiseptics creams, tablet binders, gel and thickeninig agents (Kokate et al., 2008).

\section{Gum kondagogu}

Is a naturally occurring exudates obtained from the Cochlospermum gossypium.It is composed of major neutral sugars arabinose, galactose, rhamnose, mannose, and D- glucose like dglucuronic acid D-galactouronic acid and the exudate composed of higher uronic acid content, protein, tannin and soluble fibre. Gum is sweet, cooling, and useful in treating diarrhea, dysentery, cough, pharyngitis and used in pharmaceutical aids (Bhaskar et al., 2013). It is a good emulsifying agent even at low concentration and it shows mucor adhesive properties (Mallik et al., 2012). 
BAJOPAS Volume 9 Number 2 December, 2016

\section{Xanthan gum}

Xanthan gum is a microbial polysaccharide produced from glucose fermentation by Xanthomanas lam pestris (Kokatte et al., 2008). The primary structure of Xanthan gum consists of repeating pentasaccharide units consisting of two D- glucopyranosyl units, two mannopyranosyl unit and one D- glucopyranosyluronic acid. Xanthan gum is used as suspending agent, emulsifier, stabilizer in tooth paste and ointments, emulsion and suspensions. It is also used in pharmaceutical as a sustained release agent, pellet controlled drug delivery system (Santos et al., 2005).

Tamarind gum

Tamarind gum also known as tamarind kernel powder (TKP). Tamarind gum is obtained from seed polysaccharide of tamarind tree Tamarindus indica family (Legumenoceae). The gum is obtained from the endosperm of the seed (Soni, 2002). Tamarind gum polysaccharides is pale creamy white powder without taste or odor. It is highly branched carbohydrate polymer. The chemical structure has not been fully elucidated. Methylation analysis showed D- glucopranosyl, Dxylopyranosyl- D - galactosyl, and L- arabinose components in a ratio 7:8:4:2:1 (Gidley et al., 1991). Tamarind gum is used as sizing agent for jute and cotton fabrics, as adhesive for binding papers, glass, metal and making plywood. It is also used in cosmetic, medicine and pharmaceutical industries. (Zhao et al., 2005).

\section{Cashew gum}

Cashew gum exudate is obtained from the tree Anacarduium occidentale from the family (Anacardiaceae). Cashew gum is chemically composed of $61 \%$ galactose, $14 \%$ arabinose, $7 \%$ ramnose $8 \%$ glucose $5 \%$ glucuronic acid and $2 \%$ other sugar residues. While hydrolysis of the gum yields L- arabinose, L - rhamnose, Dgalactose, and glucuronic acid (Lima et al., 2002). The dried gum is collected as air dried droplets. It has physical, chemical and rheological properties similar to gum Arabic (Okojie, 2010). It is used as a substitute to liquid glue for paper, cosmetics, in the pharmaceutical and in food industries as stabilizers (Okojie et al., 2010).

\section{Guar gum}

Guar gum is the powdered endosperm of Cymopsis tetraglonoba from the family (Legumenoceae). The endosperm contains a complex polysaccharide called galactomannan (guaran), a polymer of D-galactose and Dmannose (Laguna et al., 2003). Guar gum is a white to yellowish white powder, it is nearly odorless. Guar gum and its derivatives are among the most important water soluble polymer, mainly functions as thickner, emulsifier, stabilizer, binding agents gelling agents natural fiber flocculant agent and used in paper, textile food and cosmetic industries (Seon, 2008).

Gellan gum

Gellan gum is an anionic microbial polysaccharide secreted from Pseudomonas eloidea. It is commercially available as Kelcogel, an anionic deacetylated exocellular polysaccharide secreted by Pseudomonas eloidea with a tetrasaccharide repeating unit of one $a-L$ - rhamnose, one $\infty$ - D - glucuronic acid and two $\beta-D$ glucose chemical structure of the polysaccharide have been determine (Lahoti et al., 2011). It is used pharmaceutically as sustaining agent, floating insitu gelling, controlled released beads and disintegrating agent (Lahoti et al., 2001)

\section{Okra mucilage}

The okra mucilage is obtained from the fresh fruit of the plant Abelmuschus esculentus belongs to the family (Malvaceae), is a polysaccharide consisting of $\mathrm{D}$ - galactose, $\mathrm{L}$ rhamnose and L- glacturonic acid with some fractions of glucose, mannose, arabinose and xylose (Bhaskar et al., 2013). Okra mucilage has potential for use as food, non - food production and medicine application. Mucilage from okra is used in medicine as protective food additive against irritating and imflamatory gastric diseases, and also used to stabilize blood sugar by regulating the rate at which sugar is absorbed from the intestinal tract (Gemade et al., 2014)

\section{Psyllium mucilage}

Psyllium seed husk also known as Isagbol are portion of the seed of the plant Plantago ovate. The mucilage consist of pentason and aldobiunic acid which on hydrolysis yield arabinose, galactose, galacturonic acid and rhamnose. The gel forming fraction of the alkali extractable polysaccharide is composed of arabinose, xylose, and traces of other sugars. It is very well known and widely used in medicine as laxative to relieve constipation. It is also used in the treatment of diarrhea, inflammatory bowel, ulcerative colitis diseases, colon cancer, obesity in children and adolescent cholesterol and diabetes (Majmudar et al., 2013).

\section{Cassia mucilage}

Cassia mucilage is derived from the seed of Cassia tora belongs to the family (Ceasalpinaceae). It is locally known as charota. Cassia mucilage is used as tonic and stimulant. It contains $1-2 \%$ volatile cassia oil which is mainly responsible for the spicy aroma and taste. The primary chemicalhy constituent of cassia include Cinamaldehyde, tannin, manitol, and essential oils (aldehydes, eugenol and pinene). It also contains sugars resins and mucilage among other constituents. Seed mucilage of cassia was evaluated as suspending agent and binding agents (Sing et al., 2010).

\section{Phoenix mucilage}

Phoenix mucilage is obtained from the dried fruit of Phoenix dactylifera from the family (Palmaceae). The mucilage is brown in color and composed of amino acid and proteins carbohydrate, fatty acids, salt and minerals and dietary fiber. Carbohydrate make up to $88 \%$ which include mainly reducing sugar such as fructose, sucrose, mannose, glucose and in addition to small amounts of polysaccharide such as pectin (0.5-3.9) starch and cellulose (Gemade et al., 2014). 


\section{Fenugreek mucilage}

Fenugreek mucilage is obtained from the seed of Trignella foenum-graceum, commonly called fenugreek, is an herbaceous plant of the leguminous family. The seed of fenugreek are also used as vegetable and also functions as a preservatives and are added to pickles. The ripe fenugreek seed have few medicinal values such as treatment dysentery, dyspepsia enlargement of liver diabetis and cronic cough. It consist high percentage of mucilage which does not dissolve in water but it forms a viscous mass when exposed to other fluids (Saurabh et al., 2015).

\section{Aloe mucilage}

Aloe mucilage is obtained from the leaves of Aloe barbadensis Miller. Many compounds with divers structure have been isolated from both the central pharenchyma tissue of Aloe vera leaves and the exudates arising from the cell adjacent to the vascular bundles. The bitter yellow exudate contain 1,8 dehydroxyanthraquinone derivatives and their glycoside (Avachat, 2007). The aloe pharenchyma tissue or pulp has been shown to contain protein, amino acids protein, lipids amino acid vitamins, enzymes inorganic compound and small organic compound in addition to the carbohydrate. many investigators have identified partially acetylated mannan as the primary polysaccharides of gel, while others found pectin substances. Other polysaccharides such as arabinose, galactose, arabinorhamnogalactan, galactogalactoran, glucogalactonan, glucuronic acid containing containing polysaccharides have been isolated from Aloe vera inner leaf gel (Maru et al., 2012). $A$. vera mucilage have been used for many centuries for its curative and therapeutic properties, in pharmaceutical industries it is used for the manufacture of topical product such as ointments and gel preparation as well as in the production of tablets and capsules (Maru et al., 2012)

\section{Ocimum mucilage}

Ocimum mucilage is obtained from the seed of Ocimum americanum commonly called Ocimum canum family (lamiaceae) tha mucilage contain xylose, arabinose, rhamnose and galaturonic acid The mucilage was found to have disintegrating property (Choudhari and pawar 2014).

\section{APPLICATION OF GUM AND MUCILAGES}

Gum and mucilage of different sources and their derivatives represent a group of polymers widely used in many applications, pharmaceutical, food and non-food industries (Reddy and Manjunath 2013)

\section{Pharmaceutical application of gum and} mucilages

Gum and mucilage have a variety of applications in pharmacy. They are used in medicine for their demulcent properties for cough suppression. They are ingredients of dental and other adhesive and can be used as bulk laxative. These hydrophilic polymers useful as tablets binders, disintegrants, emulsifier, suspending agents, gelling agents, stabilizing agents, thickening agents, film foarming agents, buccal tablets as well as sustaining agents (Jani, 2009)

\section{Application in traditional medicine}

Gums and mucilages because of their non-toxicity and safe for consumption is used in costomary/traditional medication. These polymers because they contain demulcent smoothening attributes is used as cough suppressant. Mucilage can be used for the treatment of gastrointestinal inflammatory processes, used as gut soother for various other mucous membrane related problems (Herb, 2006). Local medication of gum and mucilage have been claimed to serve as smoothening and softening agents taken internally for cough, diarrhea, hemorrhage and in the treatment of local inflammation and nodular leprosy (Gindaba and Nigatu, 2007). Gum as non-timber forest product of developing countries, their uses in traditional medicine was very popular during early days, particular importance is attached to gum in Ayurvedic system of medicine for curing many diseases such as fever, sexual debilities, cough and cold dysentery and diarrhea (Sivasankar and Krishna 2014). Gum such as kondagogu is sweet and cooling and useful in the treatment of diarrhea, dysentery, cough pharyngitis as used in pharmaceutical aides (Malik et al., 2012). Mucilage such as okra mucilage used to stabilized blood sugar regulating the rate at which sugars is absorbed by the intestinal tract. Fenugreek mucilages which doesn't dissolves in water is used in the treatment in diabetes, dyspepsia, enlargement of liver and chronic cough (Saurabh et al., 2015).

\section{Application in food industries}

Various kind of gum and mucilage are used in food industries and are regarded as safe for human consumption (Deogade et al., 2012). Different gum and mucilage have different uses in food industries, they are used for water retention and stabilization,stabilize for ice cream, , meat products instant pudding, dairy, confectionery beverages and baked product, and sauces ( Choudhari, and powar 2014)

\section{Other industrial application}

New uses of gum and mucilages in other nonfood industries has increased the demand and screening of gums and mucilages in that area. Gums and mucilages are used in cosmetics, textiles (as die thickener) lithography, paints and in paper industries (as deflocculent and binder for light paper manufacturers), thickener in ceramics and confectionaries.

\section{Conclusion}

Theuse of natural gum and mucilage for various application has become very attractive because these biopolymers are economical, readily available, nontoxic and capable of chemical modification. Potentially biodegradable and with few exception biocompatible. 
Many studies have been carried out in the field of food technology, pharmaceuticals/medicine, and others using gum and mucilage. It is quite clear that gum and mucilage have advantages over synthetic ones due to their inherent characteristics. There are still many plants species containing many biopolymers that are not yet

\section{REFERENCES}

Avachat, A.M., Gujar, K.N., Kotwal, V.B., Patil, S. (2007): isolation and and evaluation of fenugreek husk as granulating agent. Indian journal of pharmaceutical science. 69(5):667-79.

Bhaskar, D.A., Uttam, K. J., Ashewat, M., jairam, C.M, Banidas, S.R (2013). Plant exudate and mucilages as pharmaceutical excipients. Jounal of Advance Pharmacy Education and research vol 3(4):387

Brindha, T. and Malika, J. (2015). GCM analysis of naturally occurring gum exudates of Azadirachta indicainternational journal of pharmaceutical chemistry 5(06).

Choudhary, P.D. and Pawar, H.A. (2013). Recently investigated gums and mucilage as pharmaceutical excipients. An overview. Journal of pharmaceutiiclecs article ID 2048499 pages.

Clifford, S.C., Arndt, M. and Jones, H.G. (2002). Mucilage and polysaccharide in ziziphus (Rhamnaceae) localization composition and physiological role during drought stress. Journal of experimental botany (53), 131138.

Deogade, M.U., Deshmic, M. V., Sakankar, M. D. (2012) Natural gum and mucilage in NDDS Application and Recent approaches. Intenational journal of pharmacy tech. research vol.4 no 2799-814.

Gemede, H. F., Ratta, N., Haki, G.D. Ashganu, W., and Fekadu, B. (2014). Nutritional quality of okra mucilage (Abemolchus esculentus): a review. Food science and quality management vol. 33.

Gindaba, J. and Nigatu, L. (2007). Potential distribution, ethnobotany and tapping procedure of gum producing Acacia specie in the Somali region, southeastern Ethiopia. East Africa journal of science vol.1(1) 69-78.

Herb (2006). [Available online] www. henriettes.herb.com/blog/mucilage.

Lima, R.D., Lima, J.R., Salis, C. R., Morewa, R.A. (2002). Cashew tree Anacardium occidentale gum as gelling agent. Biotech. Biochem. 35, 45-53.

Majmudar, H., Maniya, V., Devdhe S., Chardak R. (2013). Pharmaceutical application of ispaghula mucilage international journal of pharmaceutical science Rev. res. 18(1) 08, 4955.

Malik, S., Ashkumar, A., Munish, A. (2012). Synthesis of gum kondagogu-g-poly(N-2 investigated so far therefore studies on such sources can make an immense contribution towards this direction. Hence in the years ahead there will be a continued interest in natural gums and mucilage and their modification aimed at the development of better materials for various industrial applications.

pyrritidone and its evaluation as a mucor adhesive polymer. International journal of biological macromolecule 51(5): 756-762.

Jani, G. K., Shah, D., Prajapati, V., Jain V. (2009). Gum and Mucilages: versatile expicients for pharmaceutical formulations. Asian journal of pharmaceutical science. 4 (5): 308-322.

Krishna, N.V., Kulkani, P.K., Dixit, M., Lawanya D. and Rhabi, P.K. (2011)

Kokate, C.K., Prohit, A.P., and Ghokale, S.B. (2008). Pharmacognocy. $11^{\text {th }}$ edition. Pune Nirali Prakashani 1999: 498-

Laguna, M., Teressa, R., Tarazona, M., Pilar, S. (2003). The use of molecular dynamics for the study of solution properties guar gum. Enrique journal of chemical physics 119(2), 1148-1156.

Lahoti, S.R., Shiride, R.K., Ali, S.A. Gullecha, B. ( 2011). $\mathrm{p}_{\mathrm{H}}$ triggered sol-gel transition system of afloxacin for prolong gastric retension. Pelagia research library Der pharmacia sinica 2(5):235-250

Maru, S.G., Sapora, P., Savallya, B., Sameer, A., Nikuj, j. (2012). Natural polymer: hum and mucilage as good pharmaceutical excipient. Ph. Tech. Med. Vol 1(3).

Mazumder, R., Nath, L.K., Hagne, A. (2010). Formulation and invitro evaluation of natural polymer based microsphere for colonic drug delivery. International journal of pharmacy and pharmaceutical science vol. 2 no 1. Pp 211-219.

Orgajie, and Audu, P. (2012).Advance in natural polymers as pharmaceutical excipients: Pharm. Anal. Acta. 3:146 vol 3(1).

Okojie, V.U., Osuidi, M. O., Aighbokhian, A. (2010). A study of some physicochemical characteristics of cashew tree exudates, Anacardium occidentale. Adv. Nat. \& appl. Sci. res. Vol 8. Pp 259-263.

Prajapati, V.D., Jani, G.K, Naresh, G.M, Narayan P.R. (2013). Pharmaceutical application of various natural gums and mucilages and their modified forms. Carbohydrate polymers $92: 1685-1699$.

Rangari V.D. (2006). Pharmacognosy and phytochemistry. Nashrik India carreer publication.

Rishaba, M., ,Pranati, S., and Kulkani, G.T. (2011). Application of mucilage in drug delivery. A review. Advance In boilogical research 5(1): 1-7. 
Reddy, M. R. and Manjuath, K. (2013). Pharmaceutical natural gums, mucilages and pectins - A Review. International journal of pharmaceutical and chemical sciences. Vol 2(3).

Santos, S., Vergia, F., Pina, M. E., Sausa., J.J. (2005). Compaction compression and drug release properties of diclofenac and ibuprofen pellets comprising xanthan gum as asustained release agents. Int. $J$. Pharm. 296: 1-11

Soni, P.L. (2002). A versatile hydrocolloid tamarind kernel powder. Trend in carbohydrate chemistry 8, 119-126.

Sivasankar, M., and Krishna, M. G. (2013). Proximate analysis and standardization of plant exudates, gum olibanum and gum dikamali. Int. j. pharm. Rev. res. 24(1): 172- 176.
Saurabh, D. B., Ekta, K., Sunita, S. (2015). Natural polymer as pharmaceutical excipient and their application in different pharmaceutical formulation. A review world journal of pharmaceutical Research

Walli, T. E. (2005). Text book of pharcognosy. $5^{\text {th }}$ edition publishers and distribution. Delhi India 465, 472, 474- 477.

Zhao, Y., Yag, S., Linchan, H. (2005). Comprehensive utilization of Tamarindus indica Linn. Linchan 25(2) 122-126. 